\title{
Reading Competence of the Saudi EFL Learner: Empowering the Teachers through Linguistics
}

\author{
Fahad Saleh Suleiman Alfallaj \\ College of Sciencce and Arts, Methnab, Qassim University, Saudi Arabia \\ E-mail: parsi.gh862@gmail.com
}

Doi:10.7575/aiac.alls.v.8n.3p.12

Received: 03/03/2017

URL: http://dx.doi.org/10.7575/aiac.alls.v.8n.3p.12

Accepted: 08/05/2017

\begin{abstract}
The trend in the Reading class in KSA has been what is called 'Standards Based Proficiency' as opposed to the more desirable 'Real World Reading Requirements'. This is also where the greatest gap occurs. Whereas white collar jobs may require more reading, blue collar jobs may invariably involve reading of technical manuals and scripts where a single error can lead to disastrous results. Reading is a skill that is very much related to the real life language use by FL learners. Can this gap be closed in our educational institutions? The answer is yes as concluded by the current study that evaluates the role of Linguistics in empowering the teachers of EFL to successfully tackle the reading failure of the KSA EFL learners. Our results show that with basic training in the field teachers can bring about much change in the reading proficiency of the learners.
\end{abstract}

Keywords: Reading, Proficiency, Real life use, Linguistics, Morphology, Semantics, Syntax, Semiotics, Lexis

\section{Introduction}

Pilot studies of the EFL classrooms in Saudi Arabia have revealed that Reading is treated in an ad hoc manner with repetition taking up a large part of class time, the burden to train learners in reading being solely on the teacher and students having no opportunity to analyze their reading proficiency. At the pre university level, having taught their EFL learners the English alphabet and corresponding sounds, English teachers on the Saudi Arabian EFL canvas take their reading skills for granted. The fact that gets overlooked is that, technically speaking, one who cannot read is 'illiterate'! Further, reading is the foundation supporting instruction in all aspects of foreign language learning, whether vocabulary enrichment, picking up grammar skills, or using CALL. Moving ahead from here, there are many other reasons to know reading. We list them here:

1. Job situations will typically demand of our learners (when they look for employment), the ability to read and comprehend e mails, 'to do' lists, memos, notices and other inter and intra office correspondence. If they are not equipped with a wide array of vocabulary along with an understanding of the same, professional accomplishment will surely elude them.

2. Comprehensive reading, silent as well as aloud, helps one master the phonetics and enriches the word bank.

3. Comprehensive reading is a professional tool that empowers the EFL learners. For instance, inability to read and comprehend fully, simple instructions in the workplace can cost them their jobs while the contrary can ensure professional development and work satisfaction.

4. Reading helps the EFL learners' language faculty to grow in multiple directions. When they read silently for instance, they actually 'speak' the written word while another faculty 'listens'. Thus, three skills are enriched simultaneously in reading.

5. Finally, reading embeds possible writing patterns in the learners' minds.

Now coming to the Saudi Arabian EFL class reading scenario. In a reading class, we find that most teachers help their students reach the right answer by matching words in the question with those in the text. The reading class meant in this study is the reading course taught to intermediate level whether college graduates or not. Therefore, the type of reading here should contain four components: i. extensive reading, ii. comprehension skills, iii. reading fluently, and iv. vocabulary building. In other words, students at the intermediate level should gain such skills when they are studying the reading course. The importance of reading course to EFL learners is so obvious as already enumerated upon. It is mostly the skill where students build their vocabulary grammar and communication skills.

Study of English, or any language for that matter, has today been connected to the field of Linguistics. Semantics, Semiotics, Morphology, Syntax, Lexis, theories of cognition, psycholinguistic theories of linguistic behavior and language acquisition are only a few of the ways in which Linguistics has made forays into the field of language learning.

With these possibilities in view, this study aims to present: 1) The effectiveness of the use of linguistics in the reading class; 2) The difficulties that the Saudi students have in the reading class; 3) Recommendations to reading teachers and decision makers for better reading outcomes. 


\section{Research questions}

1. In what ways, if any, can linguistics influence teaching of reading to EFL students?

2. What are the difficulties that Saudi learners have in reading?

3. Can the reading curriculum be modified? If so, how?

\section{Literature Review}

In a study aptly titled 'Linguistic Instruction in the Teaching of Reading: Kill or Cure', Jeanette Veatch (1962) arrived at certain conclusions listed here:

i. The need for teachers to know more about linguistics is undeniable;

ii. Science of Linguistics has valid application to the classroom;

iii. The science of Linguistics has much to offer the teachers of reading and language arts.

In this quasi-experimental study to explore the impact of explicit teaching of reading strategies on EFL students' reading performance. The results showed that once trained specifically in the use of metacognitive reading strategies, the experimental group were able to perform much better post intervention.

Brown (1978) emphasized that once students are conscious of the processes, they can monitor their comprehension and apply appropriate strategies as needed for comprehending a text.

That literacy skills are developed by being given opportunities to talk about the written language is stressed by Heath (1984).

Cognitive psychologists, Brown, Armbruster, and Baker (1986) showed in their research that students learn new strategies or thinking processes most effectively when they are consciously aware of what they are doing. They say that "Metacognition plays a vital role in reading". Metacognition refers to one's understanding of any cognitive process. Two significant factors at play are knowledge of strategies, and control while reading for different purposes. Clearly, applied linguistics plays a vital role here.

Hoffman and Heath (1986) succinctly emphasized the role of linguistics in other words when they say that being taught comprehension strategies helps second language learners develop their language skills. Also important is exchange of ideas among the learners as to how they comprehend a text by applying individualized strategies.

According to Casanave (1988) interacting and talking about text in particular ways is essential to develop ESL reading ability.

Day and Bamford (1998) mentioned the benefits of extensive reading. These include fluency, vocabulary acquisition, awareness of grammar, models for writing, and an immersion in the culture of the second or foreign language.

Eskey (1986) and Anderson (2005) showed that reading faster and with greater fluency ensure effective reading. This is so as when the learners read faster, they construct meaning with thoughts as the units rather than single words. The former ensures better comprehension of the meaning.

Krashen (2003) posited that linguistic skills are developed by acquisition or learning. With this acquisition-learning hypothesis Krashen firmly placed linguistics at the centre of language learning.

Beck (2007) presented two different researches about reading in English as a second language. She introduces Goodman's ideas of reading (1967) in the area of psycholinguistics by calling reading a sort of 'psycholinguistic game', and that of Grellet (1999) in the practical area of exercising reading comprehension.

Finding effective methods of promoting second- language vocabulary acquisition seemed, for many years, to be an impossible goal. Thanks to work by Nation (2001), Coxhead (2000) and others in the last decade, word frequency lists are available that will allow teachers to focus on the words that will be the most useful for their students. Nation's approach combines direct instruction, extensive reading, and multiple exposures to the same words by any means necessary to promote learning. All in all, this school came up with a list of 2000 words occurring most frequently in the language.

Wessinger and Kiss (2013) studied the role of semiotics in EFL. They state that with global culture consciousness and intercultural citizenship coming into vogue, it is important to look at the EFL textbooks once again and see how culture figures in them and how learners engage with them. Their study looks back at studies by Street (1984) and CookGumperz (1986) who came to the conclusion that literacy is not a neutral technology, but is, in fact, a cultural artifact laden with the values and beliefs of the culture in which it arises (Street, 1984; Cook-Gumperz, 1986).

Barrot (2013) investigated the lexical and structural influence in teaching reading. She concludes that the lexical influence in teaching reading is more effective than the syntactic one.

Olson (2014) studied student perception on the use of the Linguistic speech analysis software PRAAT in second language pronunciation instruction. At the outset, he states that in Second Language Acquisition or Applied Linguistics, pronunciation or phonetics has been given a secondary role. Further that, whereas it is considered significant for the advanced learners, it is practically ignored during the first four semesters of university-level language instruction. He also reiterates that while there is a huge corpus of research in L2 pronunciation, there exists a gap between laboratory research and classroom implementation. Among other things, the study established that learners are positively disposed towards this tool as a means of improving their pronunciation. Thus, along with morphology and syntax which are major constituents of L2 classrooms, phonology and phonetics also need to be incorporated. 
In an Indonesian study, Adhyaksari (accessed 10 May 2017) concluded that applied linguistics has an important role in reading, among other things, the method of applying the material, and the principle of instruction.

\section{Methodology}

Seventy-three intermediate level English learners at Qassim University, Saudi Arabia comprised the population for this study. They are all students who have opted for the Reading course. Primary data was collected from these using a questionnaire of twenty one items dealing with the research questions of this study. It is crucial to point out that the researcher was with the participants when they were answering the questionnaire in order to clarify any item or items, especially linguistic terminologies. Each question offered only two responses: Agree/ Disagree as such bipolar responses can clearly reflect upon the usefulness of giving a linguistic perspective to the course. For this reason, the questions were worded in a clear, short, and direct manner.

\section{Interpretation of Data}

Tahaineh (2006), in a study on Word Formation Mechanisms as being significant for the L2learner

Firmly established the importance of teaching FL and L2 learners the morphological rules for word formation as opposed to the current communicative approach to foreign language teaching. He quoted methodologists and linguists as voting for vocabulary as the mechanism central to language learning. Further, himself having been a FL learner and later, teacher, he vouches for the importance of vocabulary as the most important component of any language course. Knowledge of morphology, according to Tahaineh, enables teachers and learners to classify words into usable categories.

Findings of the current study also validate the conclusions of Tahaineh. In response to item 3, 90\% of the participants $(\mathrm{N}=66)$ are of the view that they would prefer to learn new words by being shown the morphology or word formation process(s) such as coinage, derivation, compounding, clipping, blending, conversion, backformation, abbreviation, etc.

Place of pronunciation is clearly reiterated by Husain and Sajid (2015) in a study of the importance of the elements of Phonology, viz Suprasegmentals in the EFL classroom. The aspects of 'connected speech' and discourse are also stated to be of great significance in the renewed interest of language specialists in pronunciation: this is a clear departure from the Communicative Approach. They further highlight the fact that training in the use of Suprasegmentals is highly likely to aid both listening and speaking skills. Items 1, 14, 17 and 18 in the current study have been so designed to elicit their opinion on the phonological input they prefer. $77 \%(\mathrm{~N}=56)$ do not want to be taught English using the Arabic intonation, which is the prevalent practice in the system. As a result, $90 \%(\mathrm{~N}=66)$ opine that with the current training, they will not be able to produce native like speech. This result is again validated by response to item 17 , to which $84 \%$ ( $\mathrm{N}=61$ ) reported that they need to acquire native like reading ability, further supported by response to item 18 , with $92 \%$ ( $\mathrm{N}=67$ ) expressing desire to be taught native like intonation and reading.

Interplay between learners' metacognitive knowledge and control among Thai learners majoring in English has been studied by Benjaporn (2014). The results clearly established that the learners' metacognitive knowledge guided their strategy use. Responses in the current study to items 8 (75\% ie N=55 suffer from poor comprehension of the text they read); 19 ( $75 \%$ ie N=55 want the teacher to relate Arabic and English); 20 (75\% ie N=55 prefer to watch Arabic movies with English sub titles) reveal that the respondents are novice in the use of appropriate strategies to improve their reading proficiency. Training in both metacognitive knowledge and reading strategies seems to be the answer.

Fenner and Kuhlman (2012) reiterate first language not only the absolute need for English teachers to be 'highly knowledgable' about the English content and language they teach, but also, be aware of research finding in SLA and ELLs to offer the best possible language support to their learners. They advise language teachers to first undergo an introductory linguistics course that would cover Semantics among other things. With this they would be empowered to profile the learners' pronunciation (using knowledge of phonology), grammar (morphology and syntax) and vocabulary (semantics). The current study also found in responses to items 8 ('In my reading class it is easy to read but hard to comprehend' with $75 \%$ ie $\mathrm{N}=55$ of the respondents 'agreeing'); and 15 ('My course material is too difficult for me to read well' with $85 \%$ ie N=62 'agreeing'). Training teachers in the two linguistic skills of Semantics and Syntax will ensure the best learner outcomes.

Being well entrenched in the use of conversational English with the widespread use of emailing and other electronic communication modes, these learners do not encounter an obstacle so far as the English orthography goes in being the reverse of Arabic which runs from right to left.

In a research on teaching lexis to EFL students, Lee (2004) concluded that teaching lexis in the form of phrases, not as single words is the answer to the EFL learners' confounding dilemma: they spend hours learning the vocabulary but are unable to use it. Lee cites the findings of linguists who claim the significance of lexical phrases in second language acquisition: One, phrases are important because phrases are what constitute language. The other is that phrases are essential because they are useful to learners. That lexis is important is also revealed by responses to items 2,9 . $84 \%$ ( $\mathrm{N}=61)$ express a desire to learn new words in a context. $79 \%(\mathrm{~N}=58)$ of the respondents reported an inability to understand the text for want of knowing the meaning of words.

Natsir (2014) studied the role of semiotics in EFL teaching. He avers that this may be a challenging idea but is definitely beneficial because the primary role of the language learner in the language classroom to transfer and exchange correct information the audience. Semiotics is a tool that can offer teachers newer teaching models and broaden the scope of language teaching. Non-verbal and visual communication, cultural elements in semiotics and for vocabulary teaching, signs and symbols are used actively in the language classrooms. These in turn help the language learner to get to 'know more about the social and cultural cues in the target language'. He concludes with saying that 'For a better understanding in the target language, students and teachers should not only undergo training in language, 
ALLS 8(3):12-17, 2017

but also a socialising experience'. In the present study, the role of semiotics is underlined by response to item 5, with 94\% ( $\mathrm{N}=54)$ of the respondents looking for cultural familiarisation in order to understand the text.

\section{Results}

We now present the findings in tabular and graphical forms.

Table 1. Questionnaire Response

\begin{tabular}{|c|c|c|c|c|c|c|c|}
\hline \multirow[t]{2}{*}{ Item } & \multirow[t]{2}{*}{ Statement } & \multicolumn{2}{|c|}{ Frequency } & \multicolumn{3}{|c|}{ Percentage } & \multirow[b]{2}{*}{ 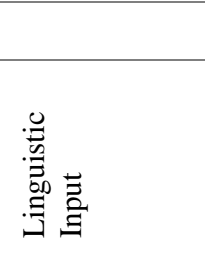 } \\
\hline & & $\frac{8}{0}$ & 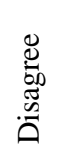 & 造 & 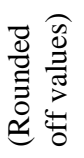 & 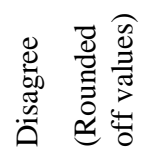 & \\
\hline 1 & I prefer that my teacher reads texts in an Arabic intonation & 17 & 56 & 23 & & 77 & $\begin{array}{l}\text { Supra- } \\
\text { Segmental } \\
\text { Features }\end{array}$ \\
\hline 2 & $\begin{array}{l}\text { Learning new words in the reading class through synonyms, opposites, } \\
\text { etc. is my preferred way to learn new words }\end{array}$ & 61 & 12 & 84 & & 16 & Lexis \\
\hline 3 & $\begin{array}{l}\text { I would like to learn the meaning of new words through 'word } \\
\text { formation' }\end{array}$ & 66 & 7 & 90 & & 10 & Morphology \\
\hline 4 & I would like to learn the meaning of new words through dictionary. & 60 & 13 & 82 & & 18 & \\
\hline 5 & $\begin{array}{l}\text { When the teacher explains the deeper meaning of the text, I am better } \\
\text { able to relate to it. }\end{array}$ & 54 & 19 & 74 & & 26 & Semiotics \\
\hline 6 & Reading is the most important skill among the language skills. & 70 & 3 & 96 & & 4 & \\
\hline 7 & $\begin{array}{l}\text { Arabic reading system (from right to left) makes reading in English } \\
\text { difficult. }\end{array}$ & 21 & 52 & 29 & & 71 & Orthography \\
\hline 8 & In my reading class it is easy to read but hard to comprehend. & 55 & 18 & 75 & & 25 & $\begin{array}{l}\text { Metacognition, } \\
\text { Semantics, } \\
\text { Syntax }\end{array}$ \\
\hline 9 & $\begin{array}{l}\text { I do not understand the text because I do not know the meaning of } \\
\text { words. }\end{array}$ & 58 & 15 & 79 & & 21 & Lexis \\
\hline 10 & I like the Reading course material used at the university. & 7 & 66 & 10 & & 90 & \\
\hline 11 & The most difficult skill in English is reading & 62 & 11 & 85 & & 15 & \\
\hline 12 & The English program should give more emphasis on reading & 67 & 6 & 92 & & 8 & \\
\hline 13 & I like to read English text fluently. & 73 & 0 & 100 & & 0 & \\
\hline 14 & $\begin{array}{l}\text { I think I will be able to read like native speaker with my current } \\
\text { training. }\end{array}$ & 7 & 66 & 10 & & 90 & Phonology \\
\hline 15 & My course material is too difficult for me to read well. & 62 & 11 & 85 & & 15 & $\begin{array}{l}\text { Syntax, } \\
\text { Semantics }\end{array}$ \\
\hline 16 & Reading is the most important skill among the language skills. & 59 & 14 & 81 & & 19 & \\
\hline 17 & Reading native-like is important for learning English. & 61 & 12 & 84 & & 16 & Phonology \\
\hline 18 & $\begin{array}{l}\text { I prefer that my teacher reads texts in an English intonation so that I } \\
\text { learn to speak like native speakers }\end{array}$ & 67 & 6 & 92 & & 8 & Phonology \\
\hline 19 & $\begin{array}{l}\text { I prefer that my teacher makes relation between reading in English and } \\
\text { reading in Arabic. }\end{array}$ & 68 & 5 & 93 & & 8 & Metacognition \\
\hline 20 & $\begin{array}{l}\text { I like to watch Arabic movies translated 'down in the screen' into } \\
\text { English to develop my reading skill. }\end{array}$ & 55 & 18 & 75 & & 25 & Metacognition \\
\hline 21 & I prefer that my teacher explains new words in English only. & 37 & 36 & 51 & & 49 & \\
\hline
\end{tabular}


Frequency of Occurence
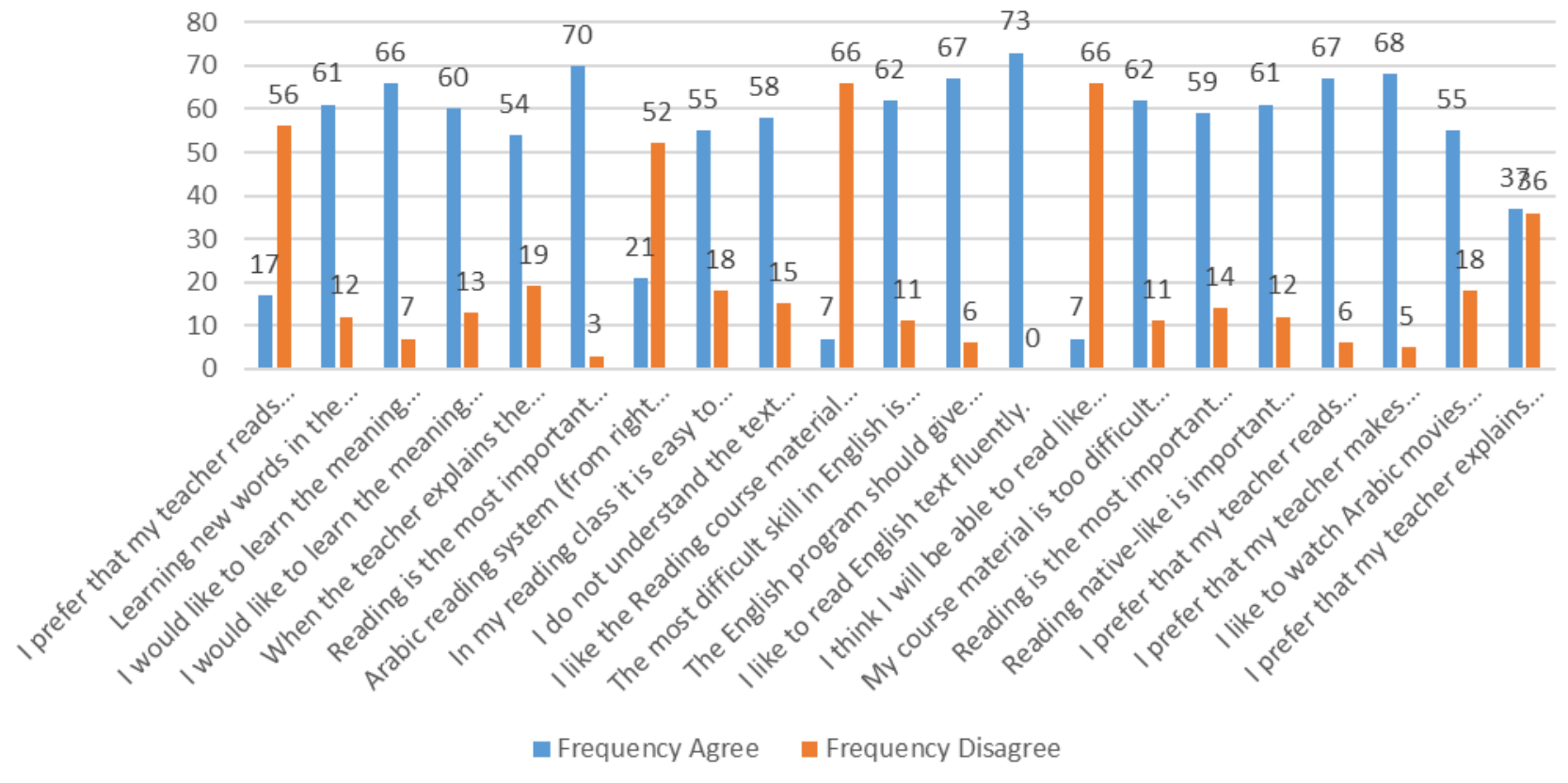

Graphical Representation 1. Response Frequency

Presented below is a Scatter Chart that compares the two sets of values obtained via the questionnaire: Percentage of respondents that Agree vs those that Disagree with an item.

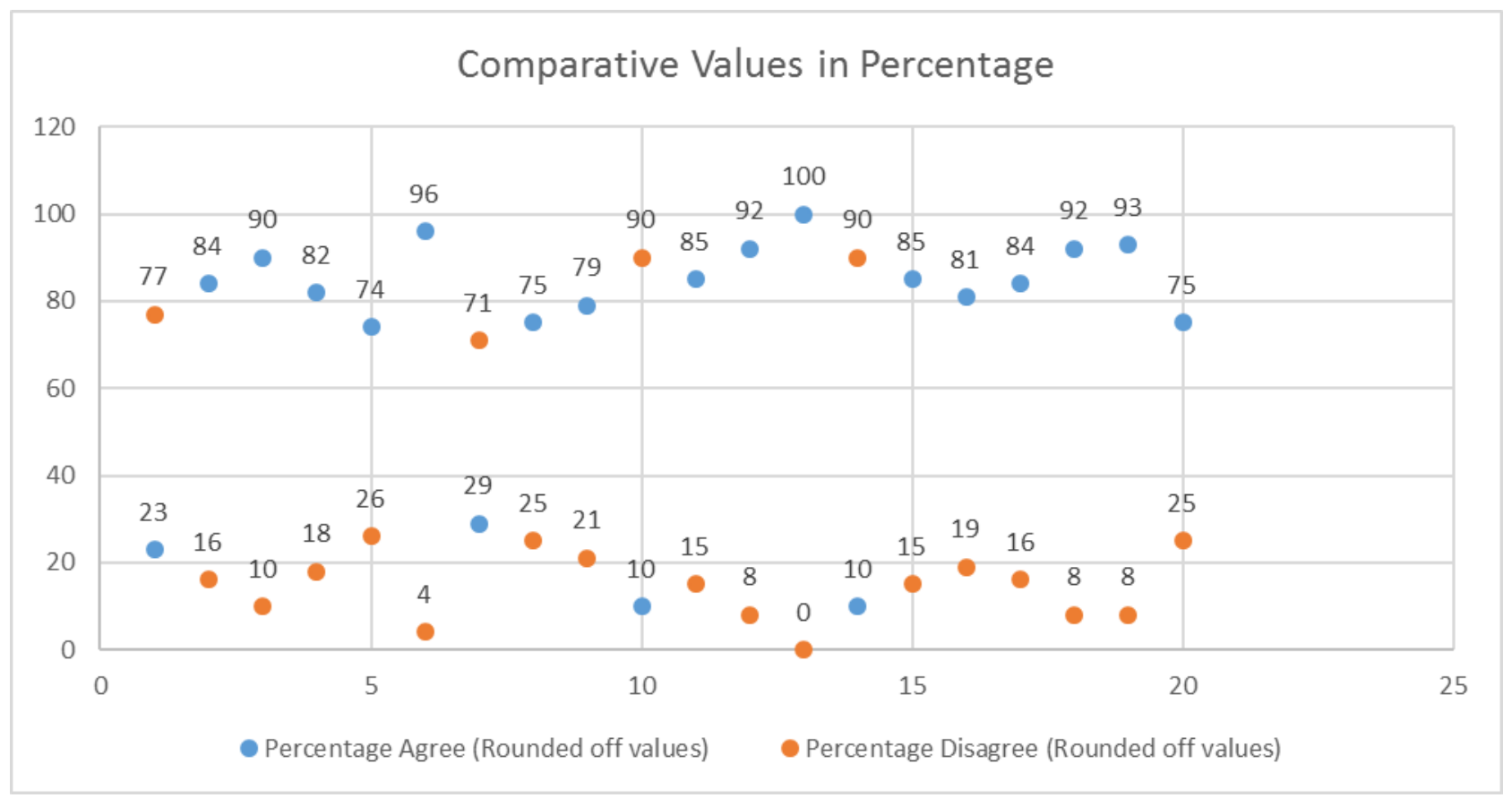

Graphical Representation 2. Comparative Percentages

\section{Conclusion and Recommendations}

Language and its learning are social processes. Further, reading as a skill, is the very essence of foreign language training. Only with a firm and well founded training in linguistics can the language teacher select appropriate linguistic material for the learners, train them in the requisite strategies and adequately assess their performance and progress. While teaching reading, teachers must remember that the long term goal is achieving native-like fluency and competence in the language. With these conclusions behind us, we recommend the following measures even as we look ahead to more extensive studies on the issue in the future:

1. The study clearly establishes that EFL teachers should be trained in the basics of Linguistics to ensure their best output in the interests of the learners.

2. Every three years, texts should be reviewed to weed our outdated sections. 
3. Reading topics of only contemporary interest to the learners should form the text.

4. Learners should be trained in reading strategies.

5. Reading should be taken up on two levels: Short passages and Longer materials.

6. Pre, post and During reading activities should be devised based upon linguistic theories in vogue.

7. Learners should be familiarised with the relevant cultural ethos related to the reading materials.

8. Teaching vocabulary in isolation should be discarded in favour of teaching phrases.

\section{References}

Anderson, N. J. (2005). Fluency in L2 Reading and Speaking. TESOL 2005 colloquium.

Brown, A. L., Armbruster, B. B. \& Baker, L. (1986). The role of metacognition in reading and studying. In Orasanu, J. (Ed.),Reading Comprehension: From Research to Practice (pp. 49-75). Hillsdale, NJ: Lawrence Erlbaum.

Casanave, Christine Pearson (1988). Comprehension Monitoring in ESL Reading: A Neglected Essential. TESOL Quarterly,22(2), 283-302 .

Coxhead, A. (2000). A New Academic Word List .TESOL Quarterly 34(2).

Day, R. (2002). Top Ten Principles for Teaching Extensive Reading Reading in a Foreign Language. University of Hawai $i$ at Manoa And Julian Bamford Bunkyo University, 14 (2).

Eskey, D. E. (1986). Theoretical foundations. In F. Dubin, D. E. Eskey \& W. Grabe (Eds.), Teaching second language reading for academic purposes (pp. 3-23). Reading, MA: Addison-Wesley.

Fenner, D.S. (2012). Preparing Effective Teachers of English Language Learners. TESOL Press.

Goodman, K. (1967). Reading: A psycholinguistic guess game. Journal of the Reading Specialist May 126-135.

Grellet, F. (1999). Developing Reading Skills. Cambridge University Press.

Heath, S. B. (1984). Literacy or literate skills: Considerations for ESL/EFL learners. In P. Larson, E. L Judd, and D. S. Messerschmitt (eds.), On TESOL 84. Washington, DC: TESOL.

Hoffman, D. M. and Heath, S. B. (1986). Inside Learners. Stanford University, Stanford, CA.

Husain, Sh., \& Sajid, S. (2015). Applocations of Suprasegmental in EFL Classroom International Journal of Scientific and Research Publications, Volume 5, Issue 9, September.

Krashen, S. (2003). Explorations in Language Acquisition and Use. Portsmouth: Heinemann.

Lee, S. (2004). Teaching Lexis To EFL Students: A Review Of Current Perspectives And Methods Annual Review of Education, Communication and Language Sciences, Volume 1.

Nation, I. (2001). Frontmatter. In Learning Vocabulary in Another Language (Cambridge Applied Linguistics, pp. IVi). Cambridge: Cambridge University Press.

Natsir, M. (2014) Semiotics And Its Roles In The Teaching Of English As A Foreign Language (TEFL) Universitas Negeri: Medan.

Olson, D. (2014). Phonetics and Technology in the Classroom: A Practical Approach to Using Speech Analysis Software in Second-language Pronunciation Instruction. Hispania, 97(1), 47-68.

Tahaineh, Y. (2012). The Awareness of the English Word-formation Mechanisms is a Necessity to Make an Autonomous L2 Learner in EFL Context Journal of Language Teaching and Research,3(6), pp. 1105-1113, November. Thepseenu, B. (2017). The role of metacognition in EFL reading comprehension : a study with Thai English major students ethos.bl.uk e thesis online service, accessed 12 may 2017.

Veatch, J. (1962). "Linguistic" Instruction in the Teaching of Reading: Kill or Cure? A Reply to "Reading Theory—An Important Distinction" Elementary English, 39(3), 231-243.

Vygotsky, L. S. (1962). Thought and Language. Cambridge, MA: MIT Press.

Weninger, C., \& Kiss, T. (2013). Culture in English as a Foreign Language (EFL) Textbooks: A Semiotic Approach. TESOL Quarterly, 47(4), 694-716.

Yossi Adhyaksari, Y.(2017). www.academia.edu, accessed 10 May 2017. 